\title{
INTERFACES DA EDUCAÇÃO DO CAMPO E MOVIMENTOS SOCIAIS: POSSIBILIDADES DE FORMAÇÃO
}

\author{
INTERFACES OF FIELD EDUCATION AND SOCIAL MOVEMENTS: \\ TRAINING POSSIBILITIES
} INTERFACES DE LA EDUCACIÓN DEL CAMPO Y MOVIMIENTOS SOCIALES:
POSIBILIDADES DE FORMACIÓN

RESUMO: O presente artigo é fruto das pesquisas realizadas em educação do campo na sua estreita articulação com os movimentos sociais, atrelada aos fatores culturais, políticos e sociais que influenciam os diferentes processos históricos de produção dos saberes. Tem como objetivo central apresentar reflexões realizadas acerca da concepção de educação do campo, no contexto dos movimentos sociais e a formação dos educadores. Utilizamos, predominantemente, a pesquisa bibliográfica e documental. Concluímos que a educação do campo, enquanto práxis libertadora, é utilizada no processo de compreensão das lutas e demandas educacionais defendidas pelos movimentos sociais. Ela dialoga com os gestos, desejos, valores e luta pela terra. Nessa conjuntura, a educação do campo pode ser ferramenta de compreensão das demandas educacionais defendidas pelos movimentos sociais do campo, colaborando com a formação continuada dos educadores.

Palavras-chave: Educação do Campo. Movimentos Sociais. Formação Docente.

ABSTRACT: This article is the result of the research carried out in rural education in its close articulation with social movements, linked to the cultural, political and social factors that influence the different historical processes of knowledge production. Its main objective is to present reflections about the conception of rural education, in the context of social movements and the formation of educators. We use predominantly bibliographical and documentary research. We conclude that field education, as a liberating praxis, is used in the process of understanding the struggles and educational demands defended by social movements. It dialogues with the gestures, desires, values and struggle for the land. At this juncture, the rural education can be a tool to understand the educational demands defended by the social movements of the countryside, collaborating with the continuing education of the educators.

Keywords: Field Education. Social movements. Teacher Training.

RESUMEN: El presente artículo es fruto de las investigaciones realizadas en educación del campo en su estrecha articulación con los movimientos sociales, ligada a los factores culturales, políticos y sociales que influencian los diferentes procesos históricos de producción de los saberes. Tiene como objetivo central presentar reflexiones realizadas acerca de la concepción de educación del campo, en el contexto de los movimientos sociales y la formación de los educadores. Utilizamos, predominantemente, la investigación bibliográfica y documental. Concluimos que la educación del campo, en cuanto praxis liberadora, es utilizada en el proceso de comprensión de las luchas y demandas educativas defendidas por los movimientos sociales. Ella dialoga con los gestos, deseos, valores y lucha por la tierra. En esta coyuntura, la educación del campo puede ser herramienta de comprensión de las demandas educativas defendidas por los movimientos sociales del campo, colaborando con la formación continuada de los educadores.

Palabras clave: Educación del Campo. Movimientos Sociales. Formación docente. 


\begin{abstract}
* Doutor em Educação/UNICAMP, Mestre em Educação/UFF, Especialista em EJA/ UFF, Graduado em História/UFF e Pedagogia/UERJ. Professor adjunto da UFRRJ. Atua na área de História da Educação, Educação do Campo, Educação e Movimentos Sociais, Educação de Jovens e Adultos e Ensino de História. Professor do Programa de Pós-Graduação em Educação Agrícola/
\end{abstract}

$1 \mathrm{MAB}$ - Movimento dos Atingidos por Barragens; CPT - Comissão Pastoral da Terra; FETAG - Federação dos Trabalhadores na Agricultura; MMC - Movimento de mulheres camponesas; MST - Movimento dos Trabalhadores Rurais Sem Terra; Caiçaras; Indígenas; Quilombolas e Ribeirinhos.

2 Com duração de quatro anos, esta licenciatura forma docentes para as áreas de Ciências Sociais e Humanidades, com ênfase em História e Sociologia. Além da formação para o ensino básico, os estudantes têm disciplinas nas áreas de agroecologia, meio ambiente, diversidade e direitos humanos.

3 Programa de Bolsas Institucionais de Extensão - BIEXT/UFRRJ 2015/2016.

4 Regimento interno do fórum de educação do campo de Nova Iguaçu / RJ. Art. $1^{\mathrm{o}}$. O Fórum de Educação do Campo de Nova Iguaçu é um órgão colegiado de natureza consultiva, de assessoramento e fiscalização, voltada ao estudo, à formulação de políticas e diretrizes para a consecução das finalidades da Educação do Campo.

5 1) Constituição da República Federativa do Brasil de 1988, Título l, Artigo $3^{\circ} \mathrm{lV}$ e Seção 1 - Da Educação, Artigo 206; 2) Lei de Diretrizes e Bases da Educação Nacional - LDB - no. 9.394/96, Artigos, 28, 78, 79; 3) ENERA - Encontro Nacional de Educadores da Reforma Agrária, organizado em 1997, pelos movimentos sociais do campo, em parceria com a UNB - Universidade de Brasília; 4) PRONERA - Programa Nacional de Educação na Reforma Agrária, criado em 1998 , junto ao INCRA - Instituto Nacional de Colonização e Reforma Agrária e o MDA - Ministério do Desenvolvimento Agrário; 5) Resolução do Conselho Nacional de Educação / Conselho Educação Básica - CNE / CEB $\mathrm{n}^{\circ}$. 1, de 3 de abril de 2002 - Diretrizes Operacionais para a Educação Básica das Escolas do Campo; 6) Programa Escola Ativa; 7) ProJovem Campo Saberes da Terra; 8) ProJovem Rural; 9) PROCAMPO - Programa de Apoio à Formação Superior em Licenciatura em Educação do Campo 10) Resolução n ${ }^{0} 4$ de 13 de Julho de 2010, que define as Diretrizes Curriculares Nacionais Gerais para a Educação Básica e, nela, a educação do campo como modalidade de ensino; 11) Decreto $\mathrm{n}^{\mathrm{o}}$ 7.352, de 4 de Novembro de 2010, que dispõe sobre a política de educação do campo e o Programa Nacional de Educação na Reforma Agrária - PRONERA e, por último, 12) PRONACAMPO - Programa Nacional de Educação do Campo, lançado no dia 20 de março de 2012.

\section{INTRODUÇÃO}

Este artigo é fruto das pesquisas realizadas em educação do campo, tendo a colaboração do Programa de Educação Tutorial (PET) na UFRRJ - Universidade Federal Rural do Rio de Janeiro. O objetivo principal é mostrar a sintonia entre os movimentos sociais do campo ${ }^{1}$ e a formação do educador, considerando a participação dos sujeitos como seres históricos e culturais. Compreendemos que a formação continuada de educadores e educandos das escolas do campo, podem estar articuladas às atividades de ensino, pesquisa e extensão propostas nas comunidades, dialogando, por exemplo, com a Licenciatura em Educação do Campo $^{2}$ e o Projeto ${ }^{3}$ : oficinas, rodas de leituras e contação de histórias na formação de professores do campo, ambos na UFRRJ, além do fórum de educação do campo ${ }^{4}$ no município de Nova Iguaçu e a pedagogia da alternância.

Trabalhamos com as possibilidades de formação dos educadores atrelada à defesa de projetos político-pedagógicos (PPP) emancipadores nas escolas do campo, considerando as histórias de vida, memórias, construção coletiva, lutas por reconhecimento identitário e novas formas de coesão social, vividas pelos movimentos sociais do campo. Acreditamos que a formação político-pedagógica deve envolver educadores/as e educandos/as oriundos dos movimentos sociais presente nas escolas do campo em assentamentos, acampamentos, territórios quilombolas, entre outros espaços. Neste debate, entendemos que as licenciaturas em educação do campo nas universidades públicas, com suas atividades de ensino, pesquisa e extensão podem ressignificar vidas.

A formação emancipadora dos sujeitos está ancorada na construção da identidade pessoal e coletiva, na centralidade do conflito de ideias e nos valores de uma nova sociedade. Nesta trabalho, nos envolvemos com os aspectos culturais vivenciados nas místicas, histórias de vida, memórias, luta pela terra e possibilidades de formação dos educadores e educandos, respeitando-se os valores éticos e solidários, além das dificuldades encontradas na consolidação dos debates acerca da educação do campo. Importante a atuação crítica do MST - Movimento dos Trabalhadores Rurais Sem Terra e da CPT - Comissão Pastoral da Terra, cobrando do poder público, ações de fortalecimento da educação pública nas escolas do campo no Estado do Rio de Janeiro. Tais escolas são assumidas com orgulho por educadores, educandos, pais, comunidades e movimentos sociais. Na construção dos referenciais teórico-metodológicos, consultamos inúmeros documentos ${ }^{5}$, alguns produzidos pelos movimentos sociais do campo, em parceria, com sindicatos, universidades públicas e secretarias municipais de educação. Comparamos e entrecruzamos vozes advindas de diversas fontes documentais escritas, enfrentando o enorme desrespeito à identidade e auto-estima dos educadores e educandos do campo. 
6 Diretrizes Operacionais para a Educação Básica nas Escolas do Campo, em 2002 (Parecer CNE/CEB no 36/2001 e Resolução $\mathrm{CNE} / \mathrm{CEB} \mathrm{n}^{\circ}$ 01/2002).
(Caldart, 2004) afirma a necessidade de assumirmos os aspectos identitários com orgulho, enfrentando os desafios presentes. A educação, como prática da liberdade (Freire, 1983), pode contribuir na formação de sujeitos que respeitem os valores sociais, culturais e histórias de vida. Nessa conjuntura, pode ainda transformar as relações de poder. A educação libertadora e a formação política, traz para o debate histórico, os aspectos relacionados à reforma agrária popular e a agricultura familiar, orgânica e agroecológica, rompendo com os agrotóxicos, pesticidas e vermicidas. O educador do campo conhecendo as histórias, individuais e coletivas, dos sujeitos, deve respeitar as diversidades, essencial na construção de uma sociedade mais justa para todos.

Por fim, nossa intenção com este artigo é revisar algumas posições encontradas acerca da educação do campo nas escolas do campo, ora de maneira muito superficial e contraditória, utilizando as palavras: educação rural, educação no campo e ensino tradicional, ora articulada à educação como prática da liberdade e às políticas públicas em educação do campo, especialmente, as Diretrizes Operacionais para a Educação Básica nas Escolas do Campo, PROCAMPO - Programa de Apoio à Formação Superior em Licenciatura em Educação do Campo e PRONACAMPO - Programa Nacional de Educação do Campo. Refletiremos sobre a educação do campo atrelada aos fatores culturais, políticos e sociais que influenciam as diferentes etapas e processos históricos de produção dos saberes, resgatando a formação docente e as transformações atuais da educação, como possibilidades de expressão da gestão democrática e emancipatória. Nessa conjuntura, os processos de formação político-pedagógica das escolas do campo estarão vinculados aos pescadores, ribeirinhos, quilombolas, caiçaras, acampados e assentados da reforma agrária, entre outros sujeitos históricos. Suas histórias de vida contribuirão para a diversidade dos debates nas escolas do campo, enquanto espaço alternativo na produção crítica e consciente do conhecimento.

\section{EDUCAÇÃO DO CAMPO E MOVIMENTOS SOCIAIS: POSSIBILIDADES DE FORMAÇÃO}

É fundamental conhecermos os princípios desenvolvidos pelos movimentos sociais no que toca à luta Por Uma Educação do $\mathrm{Campo}^{6}$. Suas bandeiras, projetos, perspectivas e utopias. A formação política dos trabalhadores e a valorização da consciência social são alguns dos desafios. Nesse sentido, a produção do conhecimento histórico pode ressignificar memórias, identidades e histórias vividas pelos sujeitos que se articulam para superar a opressão e as diversas cercas do analfabetismo, da fome e a falta de projetos emancipadores para / com homens e mulheres do campo. Essa formação política, contextualizada historicamente, pode contribuir na reconstrução do passado, 
escavando memórias e acontecimentos, recuperando documentos, fontes primárias e produção de histórias críticas e contra-hegemônicas. O conhecimento histórico construído em parceria com educandos/as, educadores/as, pais e movimentos sociais na luta por suas histórias, valores e reconhecimento, pode ser ressignificado e articulado às políticas públicas em educação do campo. Segundo (Freire, 1975, p. 39):

O opressor sabe muito bem que esta "inserção crítica” das massas oprimidas, na realidade opressora, em nada pode a ele interessar. O que lhe interessa, pelo contrário, é a permanência delas em seu estado de "imersão" em que, de modo geral, se encontram impotentes em face da realidade opressora, como "situação limite" que lhes parece intransponível.

Entendemos que a luta por uma educação do campo, incorpora a ocupação como uma das estratégias utilizadas pelos movimentos sociais. Luta popular de resistência coletiva em defesa de seus ideais, aprendizagens e construção política. O coletivo, nessa conjuntura, pode ser libertador. A organização familiar no assentamento e a conquista da escola do campo são acompanhadas por resistências múltiplas. (Abramovay, 1985, p. 57) nesse processo de organização coletiva, afirma: "os acampados, ao se organizarem coletivamente, deixam de ser apenas os objetos do processo de reforma agrária e tornam-se sujeitos, eles passam do plano receptivo para o ativo". Por outro lado, as diversas possibilidades de envolvimento geradas pelo coletivo, mostram que este não é libertador, quando as atitudes tomadas passam pelo receio de ser diferente e contrária a maioria do grupo. Não se constrói absolutamente nada de autônomo e emancipador se os sujeitos, individuais e coletivos, do campo não perceberem a necessidade do reconhecimento identitário (Honneth, 2003). Através dessa organização, os sujeitos avançam na realização dos sonhos e superação dos desafios. Para (Stédile, 1999, p. 107):

Não estamos somente preocupados com a conquista de um pedaço de terra, mas com a formação integral de toda nossa base social. Queremos ser libertos e construir comunidades bonitas, com outras relações sociais, baseadas na amizade, na solidariedade. Enfim, comunidades desenvolvidas, no sentido pleno da palavra.

Nesses espaços de luta pelo reconhecimento, presenciamos diferentes formas de resistir ao intenso calor, sob as lonas de plástico com pouquíssima iluminação, frio exagerado, doenças, fome e falta de água potável. Essas dificuldades são encontradas com bastante frequência nos acampamentos e assentamentos da reforma agrária. (Abramovay, 1985) afirma que: acampar, neste sentido, 
consiste em tomar a ofensiva da luta. É demonstrar que os agricultores são capazes de transformarem-se em agentes da construção de sua própria identidade política. Essas experiências fazem parte da organização e resistência coletiva de camponeses e educadores. Nesse contexto, as ocupações de terras, os debates sobre educação do campo e movimentos sociais, podem dialogar com a formação docente, numa perspectiva emancipadora (Karnal, 2003).

A educação do campo surge como uma dessas atividades coletivas e de ação que envolve expectativas e compromissos. Ela mostra a realidade de injustiças contra homens e mulheres do campo, desafiando o estado, representante legítimo dos interesses da burguesia. As marchas, coletivamente organizadas, podem servir como ferramentas de formação e pressão política, com atos públicos, visitas às igrejas, sindicatos, escolas e associações de moradores, envolvendo educadores, educandos, crianças, idosos e comunidades, na luta por terra e educação. Utiliza-se ainda de palestras, vídeos e caminhadas na divulgação dos valores e princípios dos movimentos sociais. Entendemos que as escolas do campo podem dialogar com essa conjuntura e contribuir para que acampados e assentados da reforma agrária deem adeus à inocência. Para Pedro Tierra (in: Fernandes, 1999, p. 153):

Quando um homem, uma mulher, um grupo de homens e mulheres, milhares de homens e mulheres e crianças naquelas horas de sombra indefiníveis, quando já não distinguirmos se ainda é noite, se já é madrugada, concentram toda a força dos excluídos em suas mãos, toda a força desse primitivo impulso de justiça que nos alimenta o coração, toda a força do sonho em suas mãos, toda força de sua classe em suas mãos, o alicate morde o fio e o arame estala como a corda de um violino e a cerca vem abaixo: eles dão adeus à inocência.

A produção crítica do conhecimento nas escolas do campo pode considerar as histórias de vida, identidades, memórias, narrativas e sentimentos de educadores e educandos, fundamentais na consolidação de projetos político-pedagógicos emancipadores. (DE Rossi, 2004); (Veiga, 2004). Na produção dos saberes históricos é extremamente necessário considerar os anseios de educadores, educandos, pais e comunidade. Pensar a educação do campo na interface com a formação docente é sempre uma decisão de coragem. Exige preparação, disciplina, maturidade política, esperança, utopia e enfrentamento das adversidades, além de efetiva participação de educadores e educandos, com tomadas de decisões, necessariamente, transparentes. O medo, a insegurança, o desgaste emocional e a dedicação fazem parte desse processo de conquistas. Os sujeitos, individuais e coletivos, são essenciais no enfrentamento das angústias, superação das dúvidas e inquietações em torno 
do projeto de vida e sociedade, defendido pelos movimentos sociais do campo. Entendemos que tais sentimentos podem ser aprofundados nas escolas do campo.

As políticas públicas em educação do campo exigem um altíssimo grau de organização, conscientização dos sujeitos, coerência com os valores e princípios defendidos pelos movimentos sociais. As reuniões, congressos, seminários, escolas do campo, universidades e licenciaturas em educação do campo contribuem no processo de fortalecimento dos educadores e educandos. Mostram o desrespeito das secretarias municipais e estaduais de educação no fechamento das escolas do campo, na utilização dos transportes e no deslocamento de educadores para áreas rurais, como forma de punição, gerando preconceitos, desavenças e desrespeito aos saberes e identidades desses sujeitos. As políticas públicas em educação do campo devem ser vistas como possibilidades de formação política e identitária, lutas e resistências almejadas pelos movimentos sociais. Ocupar o latifúndio do saber e nele produzir, é movimentar os diversos sujeitos do campo e suas experiências na luta por mais escolas, livros didáticos, educadores, educandos, merenda escolar, biblioteca, entre outros aspectos que fortalecem a estreita relação entre educação do campo, movimentos sociais e formação docente (Caldart, 2012, 2015).

Na produção crítica e coletiva do saber, a construção democrática do conhecimento pode ser compreendida com avanços e recuos entre educadores, educandos e movimentos sociais. Assim, não devemos acreditar em soluções únicas, prontas e acabadas. A fabricação de verdades absolutas e homogêneas, como anulação dos diversos saberes produzidos pelos movimentos sociais camponeses, em diferentes contextos sócio-culturais, históricos e geográficos, são atitudes repressivas e comprometedoras. A multiplicação, cada vez mais acentuada, dos debates acerca da educação do campo nos encontros regionais, estaduais e nacionais, são fundamentais para os movimentos sociais enfrentarem as dificuldades de implementação das políticas públicas. A resistência passa, necessariamente, pelos valores defendidos no campo, tais como: terra, luta, trabalho, embelezamento, cultura, vida, bandeiras, estudo, solidariedade e participação coletiva. Esses valores são frutos da convivência social, do respeito à realidade camponesa e a busca por relações, teóricas e práticas, que privilegiem a produção crítica e emancipadora do conhecimento (Santos, 2008).

A solidariedade encontra-se estampada na cozinha comunitária, nas marchas, encontros, ocupações, acampamentos, entre outros espaços de produção do saber. É tarefa da escola do campo incorporar esses valores e conscientizar educadores e educandos da desigualdade e existência de expropriados e explorados, buscando a superação dessas contradições. A escola deve cumprir o papel de proporcionar reflexões políticas e educativas que aponte caminhos de uma realidade mais humana e justa para as diversas populações do campo. Ela deve participar na 
7 Da Página do MST, 2011, 2015. Censo da Educação 2013, MEC. consolidação dos direitos, deveres, consciência e destinos vivenciados pelos sujeitos, individuais e coletivos, do campo. Para (Gramsci, 1968, p. 20):

Uma escola que dê à criança a possibilidade
de se formar, de se tornar homem, de adqui-
rir aqueles critérios gerais necessários para o
desenvolvimento do caráter. Uma escola hu-
manista (...). Uma escola que não hipoteque
o futuro do garoto, nem obrigue sua vonta-
de, sua inteligência, sua consciência e infor-
mação a se mover na bitola de um trem com
estação marcada. Uma escola de liberdade e
livre iniciativa e não uma escola de escravi-
dão e de mecanicidade.

Historicamente, existem problemas na construção de projetos que compreendam a educação do campo no Brasil e sua estreita relação com os movimentos sociais. Percebemos, por exemplo, que os contratos temporários e baixos salários dos educadores, despreparo em lidar com os saberes da terra, desconhecimento das realidades camponeses e preconceito com o meio rural, geram muitas dificuldades de trabalho, em especial, com os materiais didáticos voltados, em sua grande maioria, para escolas das metrópoles brasileiras. Importante ainda ressaltar que, boa parte das escolas do campo, encontram-se em locais de difícil acesso, comprometendo, inclusive, a orientação pedagógica e o acompanhamento dos educadores e educandos.

Reiteramos aqui os altíssimos índices de escolas do campo fechadas na última década ${ }^{7}$ (MAZUR, 2015). As turmas quando interrompidas, dificilmente retomam as atividades pedagógicas. Mais uma vez, as populações camponesas se veem em condição de desespero e negação do direito à educação do campo, novamente desrespeitado. Os gravíssimos problemas de infraestrutura nas escolas do campo, falta de formação específica dos educadores, estradas intransitáveis e ausência de transporte para realização das atividades político-pedagógicas, não podem ser encarados como "naturais". Geralmente, as linhas de transportes urbanos não fazem o trajeto até as escolas do campo, tornando o dia-a-dia de educadores e educandos, uma verdadeira aventura, com longas caminhadas, inclusive sem alimentação. Com tantos problemas, até onde vai o direito de ir e vir dos sujeitos camponeses e educadores envolvidos com os movimentos sociais e a luta por educação do campo no Brasil?

Em função da falta de formação pedagógica, muitos educadores resolvem os problemas educacionais relembrando suas experiências, quando ainda eram estudantes. Adotam táticas que pouco aguçam e contribuem para potencialidade dos educandos e sua formação crítica. Sabemos que outros agravantes interferem na (des)organização das escolas do campo, tais como: a péssima distribuição de terras no Brasil e a excessiva concentração fundiária. Esses 
aspectos demonstram as enormes injustiças sociais sofridas por milhares de pessoas em todo território nacional. (Saramago, 1997, p. 05) refletindo sobre o caso brasileiro, afirma:

Povoando dramaticamente esta paisagem e esta realidade social e econômica, vagando entre o sonho e o desespero, existem 4.800.00o famílias de rurais sem-terras. A terra está ali, diante dos olhos e dos braços, uma imensa metade de um país imenso, mas aquela gente não pode lá entrar para trabalhar, para viver com a dignidade simples que só o trabalho pode conferir.

Esta reflexão aponta para falta de alternativas de boa parte da população brasileira que, ao procurar saídas para esta triste e desumana realidade, vagam pelas estradas e lutam por terra à procura de acampamentos. São pessoas honestas que desejam trabalhar e educar seus filhos, no entanto, sem acesso à educação básica do campo (Saramago, 1997). Nessa realidade de exclusão, se deparam com desemprego, exploração e corrupção. Os poucos empregos são, geralmente, humilhantes e alienados. Nesse campo tão conflituoso, uma minoria de latifundiários mantem a mesma estrutura fundiária de séculos atrás. Historicamente, as bases das relações sociais e de propriedade não foram modificadas. A exclusão do direito à terra e educação contribui para elevadas distorções sociais e extrema violência contra os sujeitos, individuais e coletivos, nos diversos movimentos sociais. Esses são apenas alguns dos problemas enfrentados por quilombolas, ribeirinhos, pescadores, caiçaras, sem terras, agricultores familiares, indígenas, entre outros atores sociais.

Essa rápida reflexão histórica é importante para cobrar do poder público o atendimento às inúmeras exigências das escolas do campo, em sintonia com as políticas públicas de valorização da educação do campo e os diversos projetos de educação popular defendido pelos movimentos sociais. A participação coletiva dos educadores, os saberes adquiridos nas histórias de vida dos educandos e a luta pela terra, devem ser parte integrante neste processo de ensino-aprendizagem e consolidação de projetos político-pedagógicos emancipadores. As marcas dos educadores e educandos devem ser consideradas nos processos de produção da leitura, escrita e cálculos. A consolidação das políticas públicas em educação do campo passa, necessariamente, pela valorização de educadores, educandos, movimentos sociais e demais sujeitos que compõem o espaço escolar (Molina, 2010).

Para (Freire, 2001, p. 29): "O comando da leitura e da escrita se dá a partir de palavras e de temas significativos à experiência comum dos alfabetizandos e não de palavras e de temas apenas ligados à experiência do educador". As atividades pedagógicas nas escolas do campo devem 
incentivar o domínio dos códigos escritos e a valorização dos diversos saberes produzidos pelos sujeitos do campo, contribuindo, por exemplo, com a elaboração de jornais e registros de ervas medicinais nos territórios quilombolas, aldeias indígenas, acampamentos e assentamento da reforma agrária. Nessa conjuntura, que leituras e escritas circulam nas escolas do campo? Elas compreendem a estreita relação entre movimentos sociais e educação do campo? Que usos e funções elas possuem? Quais as relações políticas, pedagógicas e sociais que tornam possíveis a aprendizagem significativa, a despeito das negações e adversidades acumuladas?

Boa parte das leituras giram em torno da luta pela terra, territórios, cultura camponesa, movimentos sociais, educação do campo, pedagogia da alternância (Aparecida, 2013), fechamento das escolas do campo, combate aos agrotóxicos, fortalecimento da agricultura familiar, orgânica e agroecológica e direitos dos povos tradicionais: indígenas, quilombolas e caiçaras. Essas redes de conhecimentos nas escolas do campo, consolidadas em projetos político-pedagógicos emancipadores, rompem com o monopólio da sala de aula no processo de ensino-aprendizagem. Nesse contexto, novos elementos são acrescentados aos debates sobre a formação docente, em especial, os processos históricos, documentos orais, identidades, narrativas historiográficas, memórias, contextualizações, histórias de vida e interpretações diversas. Tal formação deve ser encarada a partir da multiplicidade de representações do real, a pluralidade das ações de educadores e educandos, as diversas modalidades discursivas, as variadas linguagens e suas inter-relações, além dos vários níveis de existência da vida social. Segundo (Hobsbawm, 1998, p. 17):

A história é a matéria-prima para as ideologias nacionalistas ou étnicas ou fundamentais, tal como as papoulas são a matéria-prima para o vício da heroína. O passado é elemento essencial, talvez o elemento essencial nessas ideologias. Se não há nenhum passado satisfatório, sempre é possível inventá-lo. [...] Nessa situação os historiadores se vêem no inesperado papel de atores políticos. Eu costumava pensar que a profissão de historiador, ao contrário, digamos, da de físico nuclear, não pudesse, pelo menos, produzir danos. Agora sei que pode. Nossos estudos podem se converter em fábricas de bombas, como os seminários nos quais o IRA aprendeu a transformar fertilizante químico em explosivo.

É necessário privilegiar na formação docente os saberes produzidos pelos educandos em seus espaços de convívio social. Os valores, hábitos, costumes, comportamentos na família, bairro, clube, igreja, escola, associação de moradores, sindicatos, partidos políticos e movimentos sociais. Entendemos que as produções culturais e pedagógicas são 
tecidas nessas interações. Assim, a produção do conhecimento histórico e crítico não pode ser baseada, apenas, em mera exposição de conteúdos, lições e exercícios de fixação. Conhecer implica ir além de tais estratégias, dialogando com propostas político-pedagógicas emancipadoras e rompendo com metodologias que privilegiem memorizações, conformismos e repetições. A formação docente exige movimentos recíprocos entre quem ensina e aprende, numa relação dialógica com o outro. Em vídeo para o MST (Freire, 1996 apud Caldart, 2000, p. 172) afirma:

Eu nunca me esqueço de uma frase linda de um educador, alfabetizador, um camponês sem-terra, de um assentamento enorme do Rio Grande do Sul aonde eu fui: Um dia pela força de nosso trabalho e de nossa luta, cortamos os arames farpados do latifúndio e entramos nele. Mas quando nele chegamos, descobrimos que existem outros arames farpados, como o arame da nossa ignorância, e então ali eu percebi, melhor ainda naquele dia, que quanto mais ignorante, quanto mais inocentes diante do mundo, tanto melhor para os donos do mundo, e quanto mais sabido, no sentido de conhecer, tanto mais medrosos ficarão os donos do mundo.

As experiências de luta por educação do campo vinculadas à ciranda infantil e educação de jovens e adultos, reconfiguraram lugares, ideias e políticas públicas. Esses espaços, com seus sujeitos políticos, contribuem na transformação da realidade de educadores e educandos, enquanto sujeitos da história. São atores que aprendem no processo de busca contínua e, não, como meros integrantes de projetos conservadores e excludentes. Aprendem nas escolas do campo, na conquista de novos territórios, na luta por educação do campo e reforma agrária popular. Neste processo, os dilemas vêm à tona e os diversos pontos de vistas aparecem, contribuindo para formação permanente do educador reflexivo e criativo. Segundo (Freire, 2001, p. 77): “A reconstrução nacional exige de todos nós uma participação consciente e a participação consciente, em qualquer nível da reconstrução nacional, exige ação e pensamento. Exige prática e teoria sempre em unidade. Não há prática sem teoria nem teoria sem prática." Partir da prática, do cotidiano, das histórias de vida e realidades de educadores e educandos, são objetivos das escolas do campo no processo de formação. Nas diversas atividades desenvolvidas pelos movimentos sociais, as experiências trazidas pelos sujeitos são valorizadas, no intuito de fortalecer a educação popular e suas possibilidades de transformação. Os princípios educativos do MST afirmam que:

Educar para a ação transformadora quer dizer que precisamos de pessoas capazes de articular, com cada vez mais competência, teoria e 
prática, prática e teoria (...) quem não sabe juntar o que estuda na escola ou num curso, com a sua vida do dia a dia, com as questões que aparecem no trabalho, na militância, nas relações com as outras pessoas, não pode ser chamado de "bem educado" e não consegue dar conta dos grandes desafios que temos no contexto social de hoje. (MST, 1999, p. 07)

Uma das preocupações presentes na educação do campo é o desafio teórico e prático da formação política. Para os movimentos sociais do campo "o grande desafio metodológico que este princípio nos traz é o de como aprender a articular o maior número de saberes diante de situações de realidade.” (MST, 1999, p. 08). A desarticulação entre teoria e prática é a principal característica do saber tradicional e conservador. Quando a produção do saber teórico dialoga com a capacitação, histórias de vida, gestos, símbolos, identidades e relação prática-teoria-prática, a práxis transformadora se consolida. A práxis surge como possibilidades de emancipação das escolas do campo, enfrentando distorções e simplificações presentes na realidade. As escolas do campo, nessa conjuntura, podem ser espaços de produção crítica e coerente do saber. Segundo (Caldart, 2000, p. 241):

O MST enxerga na escola (...) a construção histórica do valor do estudo na conformação dos sem-terra - e estudo aqui compreendido mesmo em sua ênfase (não exclusividade) na produção do conhecimento. Conhecer a realidade de forma cada vez mais ampla, profunda e em perspectiva histórica é um desafio fundamental para participação crítica e criativa de cada sem-terra na consolidação do projeto histórico do Movimento. A escola não é o único lugar onde se estuda, mas há uma associação simbólica, cultural, muito forte entre escola e estudo.

Os movimentos sociais do campo quando utilizam a nomenclatura "partir da realidade" consideram os pontos de partida e chegada, com objetivos claramente definidos. $\mathrm{Na}$ compreensão dos princípios político-pedagógicos que fundamentam a educação do campo, tal olhar é extremamente relevante. A realidade trabalhada pelos movimentos sociais deve ser conhecida e transformada. Certamente, não tem sentido conhecer todo o mundo, mesmo se fosse possível, sem antes conhecer as relações sociais e familiares, os educadores, educandos, as escolas do campo e as regiões onde os sujeitos, individuais e coletivos, resistem. Essa é uma boa oportunidade para as escolas do campo enfrentarem o modelo tradicional, livresco, conteudista e distante da realidade dos educandos/as.

É necessário romper com as formas alienantes e hegemônicas de conhecimento que massifica, pautado na decoreba, no desinteresse e tédio nas escolas. Partir do 
conhecimento mais próximo, tem se mostrado um mediador no processo de ensino-aprendizagem, transitando do particular ao geral e do geral ao particular. (Nosella, 1992), afirma que não se pode mais acreditar ou investir, num processo de formação que parta apenas da existência de uma linguagem ou conteúdos prontos e acabados, objeto de ensino do professor e apreensão do aprendiz. Não se trata mais de aprender um determinado conceito, para dele se apropriar, mas de usá-lo e, em usando-o, apreendê-lo e transformá-lo.

A valorização do trabalho agrícola, a cultura camponesa e a formação política são essenciais para pensarmos a realidade da educação do campo. Tais aspectos podem ser articulados aos conteúdos específicos das disciplinas curriculares. Educadores e educandos são convidados para debaterem os seus conteúdos específicos, projetos de vida, realidades camponesas e as lutas vivenciadas pelos sujeitos do campo. Como salienta Paulo Freire, as lições de história começam a partir da realidade do aluno e a aceitação da palavra do outro, constitutiva de nossas próprias palavras. Compreendemos que o conhecimento não está de antemão pronto, como um sistema que o sujeito se apropria para usá-lo. No processo de trocas e na atividade da linguagem, ele vai se reconstituindo. Segundo (Gramsci, 1976 apud Nosella, 1992, p. 15): "É preciso desacostumar-se e parar de conceber a cultura como saber enciclopédico, para o qual o homem é um recipiente a ser enchido e no qual devem ser depositados dados empíricos, fatos brutos e desarticulados."

Compreendemos as interfaces da educação do campo e os movimentos sociais, articulados às aprendizagens significativas, aos saberes populares e a valorização das experiências individuais e coletivas. A apropriação crítica dos conteúdos sistematizados nas escolas do campo é uma das responsabilidades de educadores/as comprometidos com a educação do campo. Respeita-se os educandos, as questões étnicas e de gênero, etnias, classe social, necessidades especiais, identidades e memórias, saberes, gestos, histórias de vida, entre outros aspectos que sinalizem a estreita relação entre teoria, prática e exercício da cidadania. Os debates nas escolas do campo devem possibilitar o diálogo e a vivência, sem restrições, com as questões práticas que envolvem a democracia, igualdade e liberdade. As possibilidades de colaboração e construção de um país socialmente mais justo estão postas. A defesa de políticas públicas que enalteça a reforma agrária popular, melhor distribuição de renda, valorização da educação do campo e os princípios educativos presente nos movimentos sociais, gera novas formas de resistências. A dignidade no campo passa, necessariamente, pela transformação das realidades conservadoras, autoritárias, individualistas, machistas e homofóbicas. Segundo o coletivo de educação do MST:

Em nossa proposta de educação, não acreditamos numa pedagogia centrada nos 
conteúdos, ou seja, naquela que considera que os conteúdos são a parte mais importante do processo educativo, sendo o seu domínio teórico a demonstração de que a pessoa está sendo bem educada. Não acreditamos nisso! Partilhamos da convicção pedagógica de que os conteúdos são instrumentos para atingir nossos objetivos, tanto os ligados ao ensino quanto à capacitação. (MST, 1999, p. 11)

Importante ressaltar que o educando carrega para escola conhecimentos historicamente construídos, em especial, suas histórias de vida, identidades e memórias na relação com a educação popular. Vivendo numa sociedade letrada, o estudante, muito antes de escrever, convive com a língua escrita e falada. Nesse sentido, as múltiplas histórias de vida dos sujeitos não podem ser negligenciadas. Deve ser constante nas escolas do campo a interação entre o que se escreve, conta, discute e sugere. Uma prática muito próxima dos conceitos trabalhados por Gramsci no livro de (Nosella, 1992, p. 38):

E vimos em torno a nós, apertados, sentados em bancos incômodos e num estreito espaço, ajuntar-se esses alunos atípicos, em sua grande maioria não mais jovens e que passaram, portanto, aquela idade quando o aprender é coisa simples e natural, todos inclusive cansados por uma jornada de oficina ou de escritório, seguir com atenção mais intensa o desenvolver-se da lição, esforçando-se de tomar nota no papel, deixando perceber de forma concreta que entre quem fala e quem escuta havia-se estabelecido uma viva corrente de inteligência e de simpatia. Isto não seria possível se nesses operários o desejo de aprender não surgisse de uma concepção de mundo que a própria vida ensinara-lhes e que sentem necessidade de esclarecer para possuí-la completamente, para podê-la plenamente atuar. É uma unidade que já existe antes e que o ensino quer reforçar, é uma unidade vivente que nas escolas burguesas em vão se procura criar.

Para (Caldart, 2000, p. 04), cada sem-terra que entra no MST entra também num mundo já produzido de símbolos, gestos, exemplos humanos, valores, que a cada ação ele vai aprendendo a significar e ressignificar. A preocupação com a construção das memórias e identidades do campo é uma necessidade nas escolas. Educadores e educandos têm a oportunidade de conhecer, discutir, refletir e opinar acerca dos seus valores, dilemas, sonhos, limites e possibilidades. Com tais comportamentos percebemos relações ampliadas de solidariedade entre os sujeitos, alicerçadas nas diversas histórias de vida. Pensar na solidariedade e no belo, tendo a possibilidade de viver e reviver sonhos e utopias, combina com a valorização constante da educação 
do campo pelos movimentos sociais. Ela alimenta a esperança de educadores e educandos. Significa paixão. Mobiliza homens e mulheres na produção crítica, consciente e emancipadora do conhecimento. É através do saber - fazer histórico que os sujeitos, individuais e coletivos, enfrentam as dificuldades, com entusiasmo frente aos fracassos e desajustes impostos pelo atual sistema político e econômico. No contato com a mística, a poesia e os sonhos, resistem às lutas e buscam uma vida mais digna. Stédile, na contracapa do livro organizado por (Bogo, 2002), afirma que:

No MST, a poesia é mais do que uma simples arte. É a forma de animar os passos na busca da terra que se distanciou dos corpos de quem precisa dela para marcar o tempo de sua existência. (...) esta pedagogia de dizer com versos está enraizada na existência de poetas e poetizas que nos antecederam e vivem em seus versos, emendados nos versos de nossos jovens e crianças que, sob as lonas pretas, não deixam de sonhar com a liberdade. A política sem poesia perde a consciência das mudanças que deve alcançar. Perdendo a consciência, perde os sentimentos. Sem sentimentos o homem vira pedra; elas não falam de si, apenas fazem a terra suportar seu peso.

Segundo (Honneth, 2003) o reconhecimento deve envolver três aspectos essenciais: a experiência do AMOR e a possibilidade da autoconfiança; a experiência do reconhecimento JURÍDICO e do auto-respeito; a experiência da SOLIDARIEDADE e a relação com a autoestima. Notamos que o desrespeito às identidades dos sujeitos do campo nos meios de comunicação, imprensa, instituições públicas e privadas na sociedade brasileira contribuem com provocações, humilhações e destruição da autoestima. Acreditamos que a esperança e a ética do ser humano deve dialogar com os sonhos, lutas e respeito aos sujeitos, individuais e coletivos. Respeito que vá além dos debates teóricos. Os educadores das escolas do campo, em sua grande maioria, compreendem a necessidade de valorização da poesia, artes, versos escritos e cantados por seus educandos. O olhar criterioso acerca das políticas públicas de educação do campo é outra preocupação estratégica desses sujeitos, relatadas nos fóruns de educação do campo e nas atividades desenvolvidas junto à UFRRJ Universidade Federal Rural do Rio de Janeiro. Esse olhar permite uma maior aproximação com a experiência do amor, da solidariedade e a luta pelo reconhecimento identitário, defendida em (Honneth, 2003).

(Caldart, 2004) sinaliza para urgência de uma pedagogia do oprimido que dialogue com a articulação nacional por uma educação do campo, com os trabalhadores/as rurais e seus diversos movimentos sociais. Uma educação que valorize os sujeitos e suas lutas sociais, numa perspectiva que contemple a formação política, emancipatória, 
histórica e identitária. A conquista da educação do campo pelos movimentos sociais é um projeto em disputa pela hegemonia, e inscreve-se como um dos componentes indispensáveis e estratégico das forças políticas, em luta pelo alargamento da democracia na sociedade brasileira, nos campos e nas cidades. As formas de pressão, de negociação, os mecanismos de decisão adotados e as tensões permanentes podem contribuir na construção da consciência crítica, conquista de direitos, coerência na utilização dos saberes e fortalecimento da autonomia intelectual de educadores e educandos.

A escola tradicional e conservadora do meio rural, historicamente, não reconheceu o potencial dos educadores e educandos, suas histórias de vida, valores e sonhos, desconsiderando diversas oportunidades de consolidação da identidade camponesa. (Honneth, 2003) sinaliza que o desrespeito à identidade pode acarretar maus-tratos práticos. São tiradas violentamente de um ser humano todas as possibilidades da livre disposição sobre o seu corpo. Representa a espécie mais elementar de rebaixamento pessoal. Esse desrespeito pode ofuscar os sentimentos e provocar a baixa-estima dos sujeitos, individuais e coletivos, distanciando-se das suas histórias de vida. Espaços de conflitos e contradições internas são criados, recusando-se as individualidades e o reconhecimento identitário. (Honneth, 2003) destaca ainda que o processo de construção e fortalecimento da identidade, pessoal e coletiva, passa necessariamente pela luta por reconhecimento.

Retomando a análise feita por (Honneth, 2003), entendemos que as escolas do campo podem contribuir com a elevação da autoestima e formação do ser humano crítico, autônomo e participação social nos espaços de integração política. É possível que tais atitudes não estejam desvinculadas da capacidade de mobilização que acampados, assentados, ribeirinhos, quilombolas, pesadores, caiçaras e indígenas constroem no seu íntimo. A educação do campo é uma conquista dos movimentos sociais e o reconhecimento identitário rompe com o tradicional isolamento e individualismo imposto pela sociedade neoliberal, contribuindo no processo de participação e cooperação entre os sujeitos. Essas experiências de reconhecimento e resistência podem ser transformadas em ferramentas de lutas, em prol de políticas públicas de educação do campo. (Molina, 2012, 2011, 2014)

Para (Honneth, 2003), a luta por reconhecimento é permeada pela valorização dos sujeitos, confiança, emoção e carências. Nessa conjuntura de debates é possível que as escolas do campo utilizem, por exemplo, músicas, danças, fotografias, vídeos e literatura como ferramentas metodológicas. Trabalha-se com a renovação dos sonhos, ideais e valores da dignidade humana, reconhecendo a realidade de vida dos educadores e educandos. As místicas, festas, confraternizações, piadas, lembranças das marchas, acampamentos e enfrentamentos com autoridades policiais, são 
incorporados como parte dos conteúdos nas escolas do campo. Espaços essenciais para o trabalho com as memórias, narrativas e contos. Importante ainda na renovação das forças, estímulo nos momentos de incertezas, dificuldades e lembranças dos antigos companheiros. Os movimentos sociais do campo, na busca contínua dos sonhos, lutas e utopias, valorizam as poesias, artes, versos e liberdade. Para o (MST, 2000, p. 19):

A música, o teatro, a dança, a pintura, poesia, as festas populares - que celebram os momentos de conquista e vitória, contribuem para desenvolver a criatividade e habilidade artística e fortalece nossa identidade histórica e cultural. É através de momentos de arte e beleza que cultivamos novos sentidos para a caminhada e preservamos nossa história.

Entendemos que as políticas públicas em educação do campo deve considerar os sonhos, as emoções e histórias de vida dos educadores e educandos, encarando-as como possibilidades de superação das dificuldades enfrentadas pelos movimentos sociais nos espaços de formação política. Dependendo do grau de envolvimento, criticidade e conscientização dos sujeitos, individuais e coletivos, os valores defendidos nas escolas do campo podem gerar alívio, tensão e respeito. Os obstáculos presentes, por exemplo, nas ocupações de terras, acampamentos, lona preta, marchas, entre outros aspectos, são enfrentados. (Caldart, 2000, p. 134) faz o seguinte questionamento: O que manteve estas pessoas em Marcha, tomando chuva, fazendo bolhas no pé, exaurindo sua força física, mesmo sabendo que ainda não era para sua terra que caminhavam? Para (Honneth, 2003), o importante é perceber os conflitos que se originam das inúmeras experiências de desrespeito e de não-reconhecimento da identidade pessoal e coletiva, atrelada a esfera emotiva, social e jurídica. Diante das dificuldades que ainda devem ser superadas, a luta pela sobrevivência individual e coletiva, passa necessariamente pelas várias cercas do judiciário, da polícia, mídia, escola e educação. Essas cercas quando derrubadas simbolizam respeito e valorização dos trabalhadores e trabalhadoras do campo. Faz a sociedade refletir sobre as imensas desigualdades em nosso país e a necessidade de valorização, entre outros aspectos, da agricultura familiar, orgânica e agroecológica, em contraposição à fome presenciada.

\section{CONSIDERAÇõES FINAIS}

As políticas públicas de educação do campo em diálogo com os movimentos sociais, constituem-se em mecanismos para fazer emergir sonhos e esperanças de educadores, educandos e trabalhadores rurais, num projeto coerente com a realidade de vida dos sujeitos, individuais e coletivos. A escola do campo na luta por inclusão social, 
diversidades, direito a terra e defesa dos direitos humanos é valorizada. Esse é um espaço de construção da cidadania plena, contrária às ações reprodutivistas e produtora de desigualdades. Entendemos que a luta por uma educação do campo, deve enfrentar as várias cercas impostas pela escola tradicional, com seus projetos autoritários e deslocados da realidade camponesa. As cercas quando derrubadas, simbolizam respeito, organização e valorização dos movimentos sociais. Faz a sociedade refletir sobre as dificuldades encontradas, em especial, a miséria, o latifúndio e o analfabetismo. As escolas do campo devem ser espaços de aprendizagens coletivas, construção política e luta pelo reconhecimento identitário, valorizando os processos de formação, as experiências educativas e o protagonismo da realidade camponesa, com suas histórias individuais e coletivas.

Percebemos que os princípios pedagógicos da educação do campo estabelece estreita relação com os movimentos sociais, considerando as diferentes realidades, os contextos históricos, as diversidades sociais e culturais. Nessa conjuntura, as escolas do campo não podem ser a mesma para pescadores, ribeirinhos, caiçaras, atingidos por barragens, pequenos agricultores, acampados e assentados da reforma agrária, aldeias indígenas, territórios quilombolas, entre outros sujeitos, individuais e coletivos, do campo. Nesses espaços, educadores, educandos, militantes, crianças, jovens e adultos aprendem, ensinam e se conhecem. Educa-se para cidadania, conscientização dos problemas e enfrentamento das dificuldades. Tais dificuldades podem ser vencidas com perseverança, dedicação, lutas, formação política, formação continuada de educadores/as e políticas públicas efetivas de educação do campo, que considerem a realidade dos movimentos sociais. Acreditamos que a práxis libertadora é uma possibilidade, quando ação e reflexão são organizadas com o objetivo de transformar a realidade dos sujeitos camponeses. Nessas alianças, a educação do campo pode ser uma das ferramentas no processo de compreensão das lutas e demandas educacionais defendidas pelos movimentos sociais.

Por fim, acreditamos que os movimentos sociais do campo, enquanto sujeitos coletivos, podem contribuir com as universidades, escolas do campo, secretarias estaduais e municipais de educação, formando educadores e educandos que respeitem as identidades dos trabalhadores rurais, lideranças comunitárias, simpatizantes da luta pela terra e educação do campo, numa perspectiva crítica e emancipadora, somados a construção de novas experiências de produção orgânica, agroecológica e cooperativa. Entendemos que os objetivos deste texto foram alcançados, privilegiando as histórias de vida de educadores e educandos, memórias e vida cultural, constitutivas de valores, conflitos de ideias, lutas pelo reconhecimento identitário e novas formas coletivas e democráticas de relacionamentos, na interface entre educação do campo e movimentos sociais. 
Quero salientar que a educação do campo não está isenta de valores e, por isso, não é neutra. Assim, a história pessoal e coletiva dos sujeitos históricos permeou o desenvolvimento desse trabalho.

\section{REFERÊNCIAS}

ABRAMOVAY, R. Nova forma de luta pela terra: acampar. Revista Reforma Agrária. (Campinas), v. 15, 1985.

APARECIDA, Maria Fonseca Cida. Pedagogia da Alternância e Educação do Campo: A formação de jovens na Escola Família Agrícola de Orizona. Ed. Novas, 2013.

BITTENCOURT, Circe M. F.(org.). O saber histórico na sala de aula. São Paulo: Contexto, 1997.

Ensino de história: fundamentos e métodos. São Paulo: Cortez, 2005. (coleção docência em formação).

BOGO, A. (org) MST: Caderno de cultura n• 1 - gerações: coletâneas de poesias. SP: 2002.

BRASIL. Constituição da República Federativa do Brasil de 1988. Título l, Artigo $3^{\circ}$ lV. Seção l - Da Educação, Artigo 206.

BRASIL. Lei de Diretrizes e Bases da Educação Nacional - LDB - no. 9.394/96. Artigos 28, 78, 79.

BRASIL. PRONERA - Programa Nacional de Educação na Reforma Agrária. INCRA - Instituto Nacional de Colonização e Reforma Agrária / MDA - Ministério do Desenvolvimento Agrário. 1998

BRASIL. Diretrizes Operacionais para a Educação Básica nas Escolas do Campo. (Parecer CNE/CEB $n^{0}$ 36/2001 e Resolução CNE/CEB no 01/2002).

BRASIL. PROCAMPO - Programa de Apoio à Formação Superior em Licenciatura em Educação do Campo. 2007

BRASIL. Resolução no 4, de 13 de Julho de 2o1o, que define as Diretrizes Curriculares Nacionais Gerais para a Educação Básica.

BRASIL. Decreto $\mathbf{n}^{\mathbf{7}} \mathbf{7 \cdot 3 5 2}$, de 4 de Novembro de 2010, que dispõe sobre a política de educação do campo e o Programa Nacional de Educação na Reforma Agrária PRONERA.

BRASIL. PRONACAMPO - Programa Nacional de Educação do Campo. 2012. 
CALDART, Roseli Salete. Pedagogia do Movimento Sem Terra: escola é mais do que escola. Petrópolis, RJ: Vozes, 2000.

CALDART, Roseli Salete; ARROYO, Miguel Gonzáles \& MOLINA, Mônica Castagna (organizadores). Por uma Educação do Campo. RJ: Vozes, 2004.

CALDART, Roseli S. PEREIRA, Isabel Brasil. ALENTEJANO, Paulo. FRIGOTTO, GAUDÊNCIO. [Orgs]. Dicionário da Educação do Campo. Expressão Popular, 2012.

CALDART, Roseli S.; STEDILE, Miguel E.; DAROS, Diana. [Orgs]. Caminhos para transformação da Escola 2: Agricultura camponesa, educação politécnica e escolas do campo. Expressão Popular, 2015.

DE ROSSI, V.L.S. Gestão do projeto político-pedagógico: entre corações e mentes. São Paulo: Moderna, 2004 .

FERNANDES, Bernardo Mançano. MST: formação e territorialização em São Paulo. São Paulo: Hucitec, 1999.

FREIRE, Paulo. Educação como prática de liberdade. RJ: Paz e Terra, 1983.

FREIRE, Paulo. Pedagogia do Oprimido. RJ: Paz e Terra, 1975 .

FREIRE, Paulo e NOGUEIRA, Adriano. Que fazer: teoria e prática em educação popular. Petrópolis, RJ: Vozes, 2001.

GRAMSCI, Antonio. Os Intelectuais e a Organização da Cultura. RJ: Civilização Brasileira, 1968.

HOBSBAWM, Eric. Sobre História. São Paulo: Companhia das Letras, 1998.

HONNETH, Axel. Luta por reconhecimento: a gramática moral dos conflitos sociais. SP: Ed. 34, 2003.

KARNAL, Leandro (org). História na sala de aula: conceitos, práticas e propostas. São Paulo: Contexto, 2003.

MAZUR, Ivania Piva. Fechamento de escolas do campo: alguns apontamentos. V Seminário Nacional Interdisciplinar em experiências educativas. Unioeste, Paraná, 2015.

MOLINA, Mônica Castagna. Contribuições do PRONERA à Educação do Campo no Brasil Reflexões a partir da tríade: Campo - Política Pública - Educação. In: Clarice Aparecida dos Santos, Mônica Castagna Molina, Sonia Meire Santos Azevedo de Jesus (organizadoras). 
Memória e história do Pronera: contribuições para a educação do campo no Brasil. Brasília: Ministério do desenvolvimento Agrário, 2010. p. 29-63.

MOLINA, Mônica C.; FREITAS, Helena C. de A. [Orgs] Em Aberto - Educação do Campo. INEP/MEC 2012.

MOLINA, Mônica Castagna \& SÁ, Laís Mourão. (Organizadoras). Licenciaturas em Educação do Campo: registros e reflexões a partir das experiências piloto. Autêntica Editora, 2011

MOLINA, Mônica Castagna. (Org). Licenciaturas em Educação do Campo e o Ensino de Ciências Naturais: desafios à promoção do trabalho docente interdisciplinar. MDA / Série NEAD Debate 23, 2014.

MONTEIRO, Ana Maria Ferreira da Costa. Professores de História: entre saberes e práticas. Rio de Janeiro, Editora Mauad, 2007.

MST - Caderno de Educação n ${ }^{\circ} 8$ - Princípios da Educação no MST. São Paulo, 1999.

MST - Cartilha de saúde $\mathrm{n}^{0} 5$. Construindo o conceito de saúde do MST. SP, 2000.

NIKITUIK, Sônia M. L. (org.). Repensando o ensino de História. Coleção Questões de nossa Época, v.53. São Paulo: Cortez, 1999.

NOSELLA, Paolo. A Escola de Gramsci. Porto Alegre: Artes Médicas, 1992.

SANTOS. Clarice Aparecida dos. (Orgs). Educação do Campo: campo - políticas públicas - educação. Incra, MDA/NEAD, 2008.

SARAMAGO, José. In: Salgado, Sebastião. Terra. SP, Companhia das Letras, 1997.

STÉDILE, João Pedro e FERNANDES, Bernardo Mançano. Brava Gente: a trajetória do MST e a luta pela terra no Brasil. São Paulo: Editora Fundação Perseu Abramo, 1999.

VEIGA, Ilma Passos Alencastro. Educação básica e Educação superior: Projeto político-pedagógico. Campinas, SP: Papirus, 2004. Coleção Magistério: formação e trabalho pedagógico. 